\title{
Age Differences on the Intention to Save in a Voluntary Retirement Fund
}

\author{
Radduan Yusof, Mohamad Fazli Sabri
}

\begin{abstract}
The Theory of Planned Behaviour (TPB) posited that an individual's intention of performing a behaviour depends on their attitude, subjective norm and the perceived behavioural control (PBC). Employing the theoretical construct of the TPB, this study aims to investigate if age moderatesthe effect of attitude, subjective norms and perceived behavioural control towards saving intention in the voluntary retirement fund in Malaysia. A quantitative approach was adopted with data collected through a nationwide self-administered questionnaire. Through a multistage proportionate stratified sampling, 384 response was collected. The multi-group permutation results confirm the differences between age groups regarding subjective norms towards the intention to save in a voluntary retirement fund in Malaysia. In the concluding remark, the implication of the study and an avenue for future research in voluntary retirement saving domain is discussed.
\end{abstract}

Index Terms: Retirement savings, Social security, Theory of Planned Behaviours, Voluntary retirement fund.

\section{INTRODUCTION}

Research around the globe revealed that many do not save enough during their working life [1]. Likewise, a problem which is prevalent in Malaysia [2]-[7]. Without enough saving, many will not be able to maintain a similar lifestyle which was led during working life and is vulnerable to poverty [8], [9]. Concurrently, the existing pension system is not able to cope with this problem, and it is not viable for governments to continue providing excessive funding for social security and pension. There is a significant concern of government around the world especially in European countries on the low levels of saving for retirement purposes which in turn, reveal a move towards a more significant role for a privately managed funded component [10], [11]. Countries, even the developed ones are opting for transferring this responsibility to individuals [12], [13]. The voluntary retirement fund, the World Bank's recommended Third Pillar social security system is often the recommended solution for most countries in facing retirement adequacy. However, since its inception in 2010 in Malaysia, the voluntary private retirement saving programs has not been successful in this country.

Whilst, the Lifecycle hypothesis suggests that different age group will be differently affected when it comes to retirement saving [14], [15]. A person will intend to even out their consumption in the best possible manner over their entire lifetimes, doing so by accumulating when they earn and dissaving when they are retired [16].

Revised Manuscript Received on October15, 2019.

Dr Radduan Yusof, Faculty of Administrative Science and Policy Studies, University Teknologi Mara (UiTM), Malaysia.

Mohamad Fazli Sabri, Deputy Dean (Post Graduate Studies \& Industry \& Community Relations) Faculty of Human Ecology, Universiti Putra Malaysia.

The lifecycle model assumed that men are rational, forward-looking and would maximise expected utility from consumption over their lifetime. The goal of saving is to appropriately estimate spending needs and assure that enough excess of income will be saved to fund the future consumption [15], [17]. Results from many types of researchshow that age and being older posit a healthy relationship with retirement saving which supports the Lifecycle hypotheses [18], [19].

Nevertheless, some economist eschews the assumptions of the life-cycle model and focus instead on psychological issues of self-control and myopic consumption of behaviour [20], [21]. The behaviourist suggested that households are not optimising life-cycle agents. Instead, they are myopic decision makers who have trouble saving for retirement and who will respond to programs that encourage self-control in setting aside assets for future consumption [20]. The behavioural life-cycle hypothesis, first proposed by Shefrin and Thaler [21], challenges many of the rational assumptions upon which the lifecycle theory is based. It explains that behaviours often found surrounding saving decisions. They claim that people do not spend times calculating a personal optimal saving rate, income flows and retirement plans. Instead, people cope by adopting simple heuristics or rule of thumbs. In explaining this behavioural phenomenon, research has employed the Theory of Planned Behavior that looks at the behavioural intention to save for retirement, specifically on voluntary retirement fund [22]-[24] and longevity annuity [25], [26]. In the TPB a function of a person's intention depends on a person's attitude, the subjective norms, and the perceived behavioural control a person has over behaviour or object. It is an indication of an individual's readiness to perform a given behaviour and assumed to be an immediate antecedent of behaviour [27]. However, most research employing the TPB to gauge the intention to save for retirement based their findings on an analysis of a single population. Studies that pooled data and assumed that a single population would behave will fail to assess if there are significant differences across two or more subgroups of data [28], [29]. By using a multigroup analysis, the differences in subsamples within the total population will be uncovered, that is not evident when examined as a whole[29]. This study intends to bridge these gaps to investigate if there are significant differences between the age group of Malaysians regarding their different perception of attitude, subjective norms, and perceived behavioural control towards behavioural intentions to save towards voluntary retirement plan using the Theory of Planned Behaviour (TPB). 


\section{Age Differences on the Intention to Save in a Voluntary Retirement Fund}

Thus, this study seeks to investigate age as a possible moderator with the intention to save in a voluntary retirement fund.

\section{LITERATURE REVIEW}

Franco Mogdiliani and his student Richard Brumberg in the 1950s when they hypothesised the theory of spending based on the idea that people will make intelligent choices about how much to spend. Modigliani proposed that a well establish empirical regularities could be accounted for in term of rational, utility-maximising consumers whom will allocate their resources optimally to consumption over their life.[15]. According to Modigliani [15], [30] over an investor's lifetime, wealth is created during years of employment when income exceeds spending. This wealth is then will be used during the years of retirement when spending exceeds income. The behaviour of individuals under this hypothesis is to manage and distribute their consumption and to save in four different stages. By maintaining a stable lifestyle, individuals will accumulate wealth while working and will dissave when they have reached the age of retirement. The consumption and saving patterns are altered according to the needs of the individuals during a different stage of lives [31]. The underlying implication of the life cycle hypothesis is that agents are forward-looking and plan consumption and saving considering their lifetime resources. Thus, they anticipated the decline in income at retirement and saved to offset the change in resources in the future [32].

While many types of research have shown a linear relationship between age and retirement planning and saving, on the contrary, considerableresearch in Malaysia has not come to the same conclusion with research from another country on the effect of age and retirement saving. Mohidin et al., [9] implied that age only acts a pure moderator on the relationship between attitudes towards personal financial planning with retirement planning behaviour. However, age does not affect retirement planning behaviour. Faezah, Talib and Manaf[33] point out in their study, there are no differences between younger and older age groups in influencing retirement planning behaviour among the EPF staff. Moorthy et al., [34] found that younger employees tend to contribute more to the retirement saving. Partly, the reason would be the different behaviour of Malaysian or perhaps, the different pension system that is available in Malaysia.

Munnell, Sundén and Taylor [35] find that age may have non-linear effects, both on participation in and contributions to $401(\mathrm{k})$ programs. They found out that the effect of age on participation declines for higher ages. Most people wait too long before establishing a personal savings program[36] and is not interested in retirement finances until they are 48 years of age [37]. On the contrary, as pointed out by Hira, Rock, \& Loibl [38] that the behavioural tendencies of young individuals (21-39 and 40-59 age group) who are active savers, seek information and starting to invest in the early age were positively and significantly related to maximisation of retirement contribution. It shows that among the age groups there may exist differences in term of retirement planning behaviour.

\section{A. Theory of Planned Behaviour}

The TPB posited that, if a person has the intention to perform a behaviour, they will typically perform the behaviour. Intention is determined by attitude, subjective norms and the perceived behavioural control of a person. Attitude has long been considered a direct and immediate cause of intention and behaviour[27], [39]-[42]. In the context of individual retirement plan saving intention, it can be assumed that if an individual is more favourable to the retirement plan, they are more motivated to save than those who are less desirable. In general, a better prepared individuals for retirements have more positive attitudes towards retirement [43].

According to the social norm hypothesis, It is predicted that the stronger the social support from friends, family, spouses or social regulation for retirement savings, the more likely an individual will save for their retirements [44]. It is an individual's perception regarding how their significant others think they should or should not conduct the behaviour [45]. If a person sees that those who are more important to them think they should perform a particular behaviour, it is highly likely that they will intend to do so. Which means, even if an individual is not favourable of the behaviour, he may conduct it nevertheless under social pressure and influence, or vice-versa [23]. Social forces may also affect retirement savings decisions because they provide a social norm indicating the "right" course of action [46].

The PBC is an individual's perception of the ease or the difficulty in performing a specificbehaviour. Which mean, the stronger an individual's PBC, the more likely they would perform the behaviour. The performance of behaviouris correlated with one's confidence in their ability to conduct the behaviour. At the same time, increased availability of resources like time, money or opportunities would improve the perceived control and hence the possibility of performing the behaviour [47]. Many experimental studies show that PBC has a direct and positive link between PBC and behavioural intention [48]-[50].

This study hypothesised that different age group could be heterogeneous in its perceptions and evaluations of attitude, subjective norms, and perceived behavioural control towards their intention to save for retirement, specifically on private retirement fund. Recognizing that the heterogeneous data structure (age) under the life cycle predict different age will act differently, it is essential to identify and understand this difference and to examine if this differences significantly exist regarding their behaviour.

The model in figure 1 investigates if age act as a moderating factor interacts with the TPB variables and change or strengthen the direction regarding saving intention in the private retirement fund. By looking at the perspective of the different age group in this model will able to gauge if attitude, subjective norms, and $\mathrm{PBC}$ is affected by age towards an intention to save for retirement. 


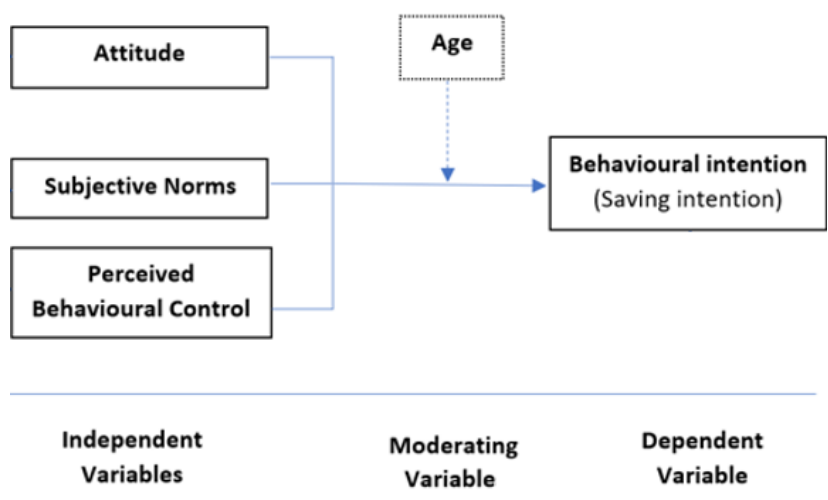

Figure 1Conceptual Framework

Analysis on the full set of data, assuming that data stem from the homogenous population is often unrealistic. Pooling data across observations is likely to produce misleading results. Failure to consider such heterogeneity can be a threat to validity and leads to incomplete PLS-SEM results since it can lead to incorrect conclusions[51]. Group-related differences in model estimates can cancel each other out, yielding non-significant effects when analysing data on the aggregate level. Failure to consider this can be a threat to the validity of partial least squares structural equation modelling (PLS-SEM) results [52], [53] and can give a valuable insight of the interpretation of the TPB when age is being considered as a significant moderator. Therefore, it is hypothesised that;

H1: There is a significant difference between the effect of attitude towards the intention to save in a voluntary private retirement fund between the young and older group.

$\mathrm{H} 2$ : There is a significant difference between the effect of subjective norms towards the intention to save in a voluntary private retirement fund between the young and older group.

H3: There is a significant difference between the effect of perceived behavioural control towards the intention to save in a voluntary private retirement fund between the young and older group.

\section{METHODS}

This study employs quantitative research using a cross-sectional survey approach to determine the characteristics of the population. The moderating effect is assessed using Henseler et al. [54] Multigroup analysis approach (MGA) via PLS-SEM through the MICOM Procedures. The survey questionnaire was made in English and was back to back-translated to Bahasa Malaysia and retranslated to English guided by language experts. 60 respondents were chosen conveniently from Facebook with 25 of them answered. The questionnaire was then proofread by six academics and two professionalswhoare an expert in the area to affirm the strength and the language of the questionnaire. The questionnaire where then pilot tested in fieldwork to 80 respondents with 39 returns to report the Cronbach Alpha which then was used to correct and make refinement to the questionnaire

A suggested minimum sample size for a PLS-Sem analysis using the G-Power analysis (one-tailed, effect size $=0.3$, alpha err prob $=0.05$, power $(1-\mathrm{B}$ err-prob $=0.85)$ ) is 75 cases or using Chin [55] 10 times per most substantial number of paths from the independent variable going into a dependent variable is 30 (constructs to attitude). The final questionnaire sent and data was collected the first quarter of 2018 using purposive multistage stratified sampling. One thousand two hundred questionnaires were distributed by post to 120 agencies with a public-private sector ratio of 20:80 throughout the 14 states of the Peninsula. The agencies were selected randomly through Google Search using a random number generator. Each envelope contained ten sets of English and Bahasa questionnaires, depending on the type and location of the agencies. The selected agencies were contacted before sending out the questionnaire. The representatives were called again to confirm that the questionnaire has been sent out, and another call to remind them to return the questionnaire. Out of these, 61 agencies participated, and 484 questionnaires were returned ranging from 4 to 15 cases per agency. Upon refinement of the cases, 334 usable set were used for analysis after the deletion of the non-subject respondent, already have voluntary saving, straight lining unengaged respondent, missing value more than $10 \%$ or missing all items in single construct and items-based z-score outliers and Mahalanobis' Distance multivariate outliers.

The items measure of attitude, subjective norms, and perceived behavioural control are adapted from Croy[56], [57], and Mahlanza[22]. All the items in the construct are reflective measure. The participants answered a completed questionnaire with 5 points Likert's scale (1=strongly disagree to $5=$ strongly agree, with no indicator in between) in the survey to measure the constructs. The initial Cronbach's Alpha value for each construct are: Intention (.93); Attitude (0.82); Subjective norms (0.89); and PCB (0.75); All items meet the 0.7 reliability [58]. Although, the Cronbach Alpha's value meets the requirement for construct reliability, however, some items are deleted from the final analysis due to poor loadings, lateral and vertical collinearity issue to fit the requirement in the PLS-SEM measurement model.

\section{A. Multigroup Analysis Approaches}

Multigroup analysis is a between-group analysis is used to test a predefined data groups to determine if there are any significant differences in group-specific parameter estimates such as the outer weights, outer loadings, and path coefficient of an identical model of two different group [29], [59]. The multigroup invariance test in the measurement and structural model determine that the difference observed was due to the true differences and not because of difference psychometric response between the groups. The measurement model multigroup invariance indicate the items used mean the same thing to respondent in a different group or population while the structural model invariance indicate whether the structural paths are equivalent across groups [60]. Assessing the difference can be done with either bootstrapping or permutation result. According to Hair et al., [61], the MGA is an efficient way to assess moderation across multiple relationships as opposed to standard moderation, which examines a single structural relationship at a time [61]. 


\section{Age Differences on the Intention to Save in a Voluntary Retirement Fund}

In this study, the moderating effect is assessed following the guidelines of Henseler's et al. [54] Multigroup analysis approach (MGA) via PLS-SEM through the MICOM Procedures.

\section{RESULTS}

\section{A. Generating Data Groups Based on Categorical Value}

The 484 respondents for this study ranges from 21 to 60 years old. After data screening (missing values, unengaged respondent, non-respondent, outliers) the cases for analysis is 334. The age group were divided into two groups (Young Respondent and Older Respondent).

1. Group 1: 30 and below (Younger Respondent) $=156$ cases

2. Group 2: Above 30 (Older Respondent) $=178$ cases

The category is to differentiate between young respondent at their early career, adult's respondent and older adults. Each of the subpopulationsexceeds the minimum for the theoretical model that has a maximum ofthree arrows pointing at a construct (intention) in the Chin [62] recommendation. The minimum $\mathrm{R} 2$ for the most arrows pointing to a construct is the intention $(10 \%$ with a minimum $R^{2}$ of 0.5$)=30$ [62]. In order to exceed the minimum $R^{2}$ of 0.5 at a $5 \%$ significance level, both subgroups would need to exceed 38. The younger respondents are assumed to start their career, while the older respondent is assumed to have a more stable term of their career development. The theoretical model includes three constructs: Attitude, Subjective Norms and Perceived Behavioural Control. Data are all reflective which are all antecedent of Intention. Measurement model analysis has to ensure validity and reliability requirements for each subsample [29], [61]. Item reliability demands to remove items with factorial loadings lower than 0.5 in all two subgroup models to guarantee configuration invariance for multigroup analysis [63]. Since no loadings in the prior measurement model are less than 0.5 . Therefore no changes were made to it.

\section{B. Micoms three-step procedure}

Before comparing group-specific parameter estimates for significant differences using MGA is to ensure measurement invariance (also referred to as measurement equivalence) to provide confident that group differences in model estimate do not result from the unique content and or meaning of the latent variables across groups. When measurement invariance is not present, it can reduce the power of statistical tests, influence the precision of estimators and provide misleading results [29], [54], [64], [65]. MGA requires establishing measurement invariance to ensure the validity of outcomes and conclusions.

Measurement invariance (also referred to as equivalence) is to determine that the measurement models specify measures of the same attribute under different conditions. When measurement invariance is established, it is concluded that different model estimation parameters are not the result of the distinct content or meaning of the latent variables/constructs that comprise the measurement model of any one group [28], [66]. Additionally, by not establishing invariance in the measurement model constructs, measurement error may be introduced leading to biased results [67]. Therefore, when analysing differences between groups, type II errors are minimised[67], and the resulting differences are the result of actual group-specific differences in the parameters and not measurement invariance (Henseler et al. 2016).

Henseler, Ringle and Sarstedt[68] developed the measurement invariance of the composite model (MICOM) procedure for PLS-SEM since the common factor models approach created by Steenkamp and Baumgartner [69] and Vandenberg and Lance [70] and the related extensions to the formative measurement model [71] cannot be readily transferred to PLS-SEM's composite models. The MICOM procedure talks about composites when referring to the entities (scores) the PLS-SEM algorithm uses to refer to the latent variables as specified by the researcher. The MICOM Procedures involve three hierarchically interrelated steps which will be discussed in the following subsection.

\section{a) Configural Invariance}

The configural invariance consists of the evaluation of the measurement models for all groups to determine if the same factor structure exists in all groups [64]. In this step, caution was taken to ensure the analysis have identical indicators, equal data treatment and the same algorithm settings/ criteria. If measurement invariance is established, it can be concluded that different model estimation parameter is not the result of the different content or meaning of construct in the measurement model [54], [62]. The data used for this analysis were screened for outliers and missing data. The group-specific data are taken from the same survey, thus having identical indicators.

b) Measurement Model

The group-specific differences for each groupwere analysed separately shows the measurement model evaluation using the guidelines by Hair et al., [61] fulfilled the reliability and validity of the model. Initially, the AVE for perceived behavioural control in the measurement model for Group 1 (30 and below) does not achieve the 0.6 thresholds for convergent validity. Thus an item was deleted (PBC4RC) because of poor loading. Deletion of the item increases the AVE of PBC for Group 1 from 0.563 to 0.621 and group 2 from 0.637 to 0.702 as shown in Table 1 . The new measurement model for the moderation analysis meet the commonly suggested criteria for measurement model assessment. The comparison of the measurement model between the complete, Group 1: Age 30 and Below and group 2: Age Above 30 indicate that items loading for group to be compared achieved items loadings above the 0.6 as a threshold value, if the loading contributes to AVE scores of greater than 0.6 (Byrne, 2016). The Rho A > 0.7 indicates indicator reliability [58], Composite Reliability (CR) > 0.7 indicates internal consistency [72].

The discriminant validity shows no issues on the cross loading and Fornell-Larcker's criterion. The results of the measurement model for each of the subsamples were also found to be valid according to the commonly accepted guidelines (Hair et al., 2014). 
Table 1 Measurement model for Group 1 (30 and Below) and /Group 2 (Above 30)

\begin{tabular}{|c|c|c|c|c|}
\hline \multirow{2}{*}{$\begin{array}{l}\text { Group } \\
\text { Indicator }\end{array}$} & \multicolumn{4}{|c|}{ Group 1: 30 and Below/ Group 2: Above 30} \\
\hline & Loadings & Rho A & CR & AVE \\
\hline \multicolumn{5}{|l|}{ Intention } \\
\hline INT1 & $0.924 / 0.921$ & $0.925 /$ & $0.952 /$ & $0.868 /$ \\
\hline INT2 & $0.944 / 0.967$ & & 0.956 & 0.880 \\
\hline INT3 & $0.927 / 0.925$ & & & \\
\hline \multicolumn{5}{|l|}{ Attitude } \\
\hline ATT1 & $0.826 / 0.906$ & $0.900 /$ & $0.912 /$ & $0.637 /$ \\
\hline ATT2 & $0.823 / 0.857$ & 0.929 & 0.935 & 0.710 \\
\hline ATT3 & $0.899 / 0.914$ & & & \\
\hline ATT4RC & $0.712 / 0.712$ & & & \\
\hline ATT5 & $0.843 / 0.916$ & & & \\
\hline ATT6RC & $0.661 / 0.721$ & & & \\
\hline \multicolumn{5}{|c|}{ Subjective Norms } \\
\hline SN1 & $0.848 / 0.820$ & $0.885 /$ & $0.918 /$ & $0.738 /$ \\
\hline $\mathrm{SN} 2$ & $0.877 / 0.904$ & 0.894 & 0.925 & 0.755 \\
\hline SN3 & $0.863 / 0.891$ & & & \\
\hline SN4 & $0.847 / 0.857$ & & & \\
\hline \multicolumn{5}{|c|}{ Perceived Behavioural Control } \\
\hline PBC1 & $0.824 / 0873$ & & & \\
\hline PBC2 & $0.836 / 0.868$ & $\begin{array}{r}0.801 / \\
0.861\end{array}$ & $\begin{array}{r}0.867 / \\
0.904\end{array}$ & $\begin{array}{r}0.621 / \\
0.702\end{array}$ \\
\hline PBC3 & $0.826 / 0.862$ & & & \\
\hline PBC4RE & -/- (omitted) & & & \\
\hline PBC5 & $0.650 / 0743$ & & & \\
\hline
\end{tabular}

c) Structural Model

The structural model assessment for the specific group was done with 5000 bootstrapping resample, two-tailed test at a 0.05 significance level as suggested by Matthews [29]. Table 3 shows that all three of the antecedent of saving intention, namely attitude, subjective norms and perceived behavioural control are significance for both Groups 1 (30 and Below) and Group 2 (Above 30). Path analysis results show that both below 30 and above 30 indicated a positive influence of attitude, subjective norms and perceived behavioural control towards saving intentions. However, dividing the group into two different age group shows an interesting contradiction. Only group below 30 follows the important path in the general model $(\beta ; \mathrm{PCB}=0.457$, attitude $=0.204$, and $\mathrm{SN}=$ 0.187). Whereas in the older group, the most important determinant for behavioural intention is not $\mathrm{PBC}$, but their attitude $(\beta$; Attitude $=0.389, \mathrm{PCB}=0.279, \mathrm{SN}=0.184)$. In both occasions, subjective norms remain the least important determinant.
Table 2 Discriminant Validity for 30 \& Below and Above 30
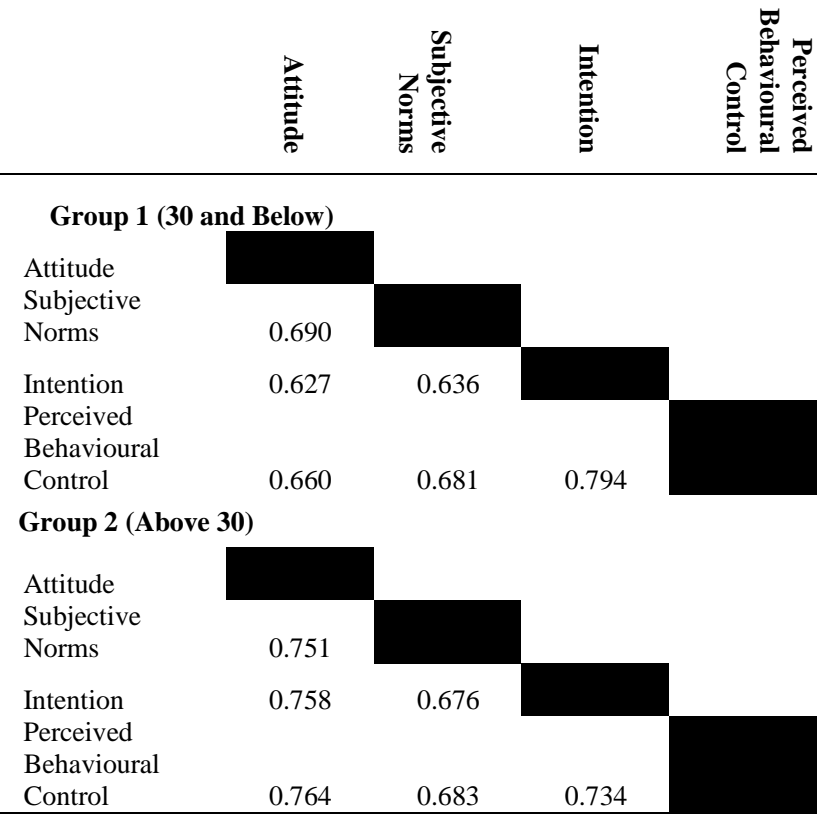

\section{Compositional Invariance}

The compositional invariance occurs when the composite scores are created equally across groups [54]. At the same time, second assessment for compositional invariance through a non-parametric permutation test are also conducted which compares scores of the first and second group. The process involves comparing the correlations between the composite scores using the weight obtained from the first group against the composite scores using the weights obtained from the second group [54].

The MICOM results report for step 2 in Table 4 shows if an original correlation of any variable is equal to or higher than the $5.00 \%$ quantile correlations indicate that composition invariance has been demonstrated for that construct. All variables must achieve the recommended value, only then the MICOM STEP 2 is achieved [29]. This permutation test is to determine if the correlation $C$ is significantly different from the empirical distribution of $C_{u}$ which is represented by the $5 \%$ quantile [54]. Since the composition invariance shows no problem in any of the construct, thus no items or construct were deleted at this stage. The next stage is to evaluate the construct composite's equality of mean values and variance across the groups.

Invariance is established when the mean original difference in the first column must fall within the $95 \%$ confidence interval by comparing the mean original difference of the lower (2.5\%) and upper (97.5\%) boundaries. If any construct does not fulfil this condition, the second step is to compare the original variance difference which the number must fall within the $95 \%$ confidence interval in order to conclude full measurement invariance of the composite. If step 1 and step 2 are established, a full or partial measurement invariance is confirmed. 
Age Differences on the Intention to Save in a Voluntary Retirement Fund

Table 3 Bootstrapping results for 30 \& Below and Above 30 separately

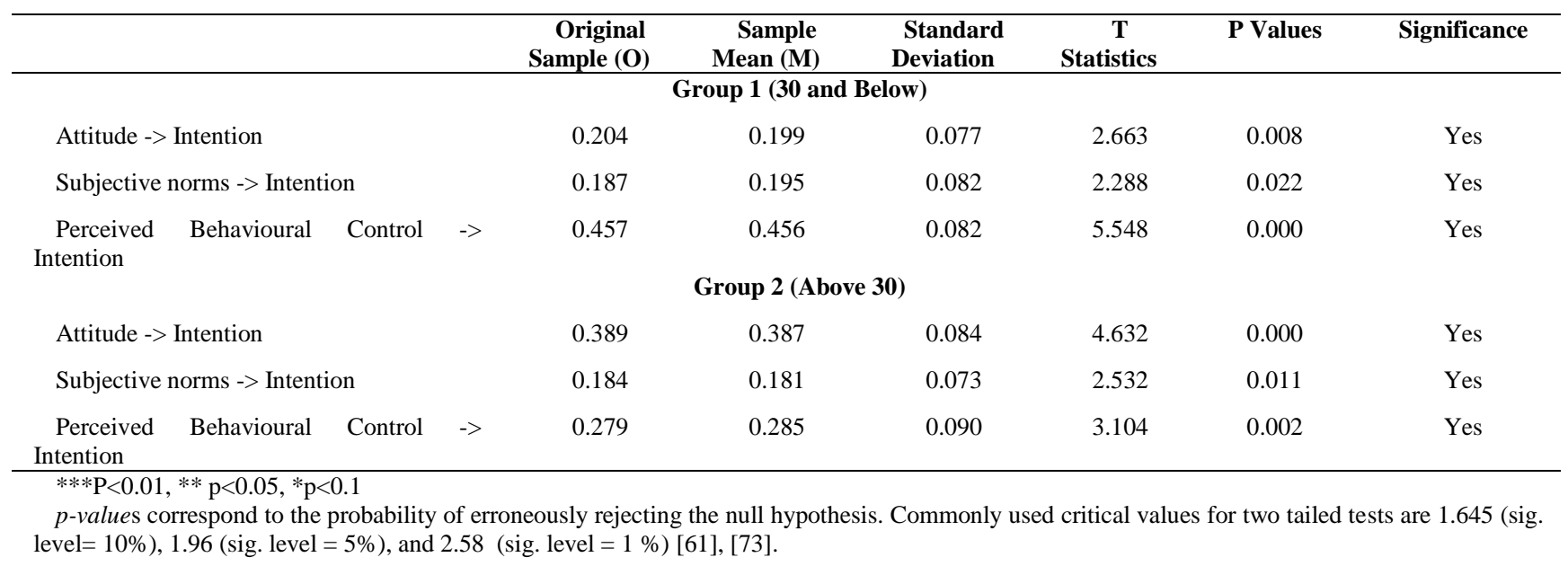

Table 4 MICOM Step 2 results report

\begin{tabular}{|c|c|c|c|c|c|}
\hline & $\begin{array}{c}\text { Original } \\
\text { Correlation }\end{array}$ & $\begin{array}{c}\text { Correlation } \\
\text { Permutation Mean }\end{array}$ & $5.0 \%$ & $\begin{array}{c}\text { Permutation } \\
\text { p-value }\end{array}$ & $\begin{array}{l}\text { Compositional } \\
\text { invariance? }\end{array}$ \\
\hline intention & 1.000 & 1.000 & 1.000 & 0.552 & Yes \\
\hline Attitude & 0.999 & 0.999 & 0.998 & 0.170 & Yes \\
\hline Subjective norms & 1.000 & 0.999 & 0.998 & 0.883 & Yes \\
\hline perceived Behavioural control & 1.000 & 0.999 & 0.997 & 0.958 & Yes \\
\hline
\end{tabular}

Table 5 MICOM Step 3 results report - Part 1

\begin{tabular}{|c|c|c|c|c|c|}
\hline & $\begin{array}{l}\text { Mean - Original Difference } \\
\text { (30 and below - Above 30) }\end{array}$ & $\begin{array}{c}\text { Mean - Permutation Mean } \\
\text { Difference (30 and below - } \\
\text { Above } 30)\end{array}$ & $2.5 \%$ & $97.5 \%$ & Permutation $p$-Values \\
\hline Intention & -0.114 & -0.003 & -0.214 & 0.208 & 0.297 \\
\hline Attitude & 0.001 & -0.001 & -0.211 & 0.217 & 0.996 \\
\hline Subjective Norms & 0.093 & -0.001 & -0.210 & 0.212 & 0.395 \\
\hline $\begin{array}{l}\text { Perceived Behavioural } \\
\text { Control }\end{array}$ & -0.322 & 0.000 & -0.211 & 0.219 & 0.003 \\
\hline
\end{tabular}

Table 6 MICOM Step 3 results report Part 2

\begin{tabular}{|c|c|c|c|c|c|}
\hline & $\begin{array}{l}\text { Variance - Original Difference } \\
\text { (30 and below - Above 30) }\end{array}$ & $\begin{array}{c}\text { Variance - Permutation } \\
\text { Mean Difference } \\
\text { (30 and below - Above 30) }\end{array}$ & $2.5 \%$ & $97.5 \%$ & $\begin{array}{l}\text { Permutation } \\
p \text {-Values }\end{array}$ \\
\hline Intention & -0.071 & 0.001 & -0.306 & 0.307 & 0.658 \\
\hline Attitude & -0.146 & 0.002 & -0.304 & 0.303 & 0.348 \\
\hline Subjective Norms & -0.244 & 0.000 & -0.251 & 0.256 & 0.059 \\
\hline $\begin{array}{l}\text { Perceived Behavioural } \\
\text { Control }\end{array}$ & -0.028 & 0.000 & -0.269 & 0.258 & 0.840 \\
\hline
\end{tabular}


Table 7 Multigroup Permutation Test-Path Coefficient ( $\beta$ ) Results

\begin{tabular}{|c|c|c|c|c|c|c|c|}
\hline Relationship & $\begin{array}{c}\beta \\
\text { (Group } \\
1)\end{array}$ & $\begin{array}{c}\beta \\
\text { (Group } \\
2)\end{array}$ & $\begin{array}{c}\beta \text { Diff } \\
{[\text { Group 1 }} \\
- \text { Group 2] }\end{array}$ & $\begin{array}{l}\beta \text { Permutation Mean } \\
\text { Difference ( } 30 \text { and } \\
\text { below - Above } 30)\end{array}$ & $2.5 \%$ & $97.5 \%$ & $\begin{array}{c}\text { Permutation } \\
\text { p-Values }\end{array}$ \\
\hline (H1) Attitude -> Intention & 0.204 & 0.389 & -0.184 & 0.000 & -0.237 & 0.241 & 0.133 \\
\hline $\begin{array}{l}\text { (H2) Subjective Norms -> } \\
\text { Intention }\end{array}$ & 0.187 & 0.184 & 0.003 & -0.001 & -0.209 & 0.209 & 0.976 \\
\hline (H3) Perceived Behavioural & 0.457 & 0.279 & 0.178 & 0.002 & -0.257 & 0.260 & 0.188 \\
\hline
\end{tabular}

Passing any one of thesetests means partial measurement invariance is achieved. If both of the variable or construct does not pass any of this test meaning measurement invariance is not achieve, and the multigroup analysis should not proceed [29]. In other words, if we do not look at the invariance differences, we cannotassume that the groupdifferences are between the traits, instead because of measurement issues. The path relationship shows that Perceived Behavioural Control did not meet the construct composite's equality of mean values as shown Table 5 but met the construct composite's equality of variance values as shown in Table 6 in the first part of the MICOM step 2 report. The value of this variable does not straddle in between the $2.5 \%$ and $97.5 \%$, but the variance original differences value for these three variables straddle in the $2.5 \%$ and $97.5 \%$ variance permutation differences. On the other hand, the construct for subjective norms did not meet the requirement

for the construct composite's equality of variance values but passed the construct composite's equality of mean values as difference in the composites' equality of mean values and variances across groups. The part 1 and part 2 of MICOM's step 3 shows none of the variables did not meet the equal mean and equal variance in combination. Therefore, this model achieved partial invariance, which mean each construct does not have significant differences in the composites' equality of mean values and variances across group and invariance is established for this model.

The permutation test is the more conservative permutation test compare to the parametric test and hasbetter control of the type 1 error [29]. This permutation test determines if the differences between the two groups are significant by comparing the output for the permutation test which was obtained as part of testing for measurement invariance. A permutation $\mathrm{p}$-value of less than or equal to 0.05 and p-value higher than or equal to 0.95 ( $\mathrm{p}$-value $<0.05$ or $>0.95$ ) shows a significant difference between the two groups [54]. Table 7 shows one of the path relationships between subjective norms (H2) towards intention is having a permutation $p$-value equal to or above 0.95 . On the other hand, the results indicate there are no significant differences between the age group regarding their attitude and perceived behavioural control towards their saving intention. The decomposition of these constructs into its corresponding specific belief shows that no significant difference of the construct between both groups.

The information from the group-specific bootstrapping shows there are slightdifferences between attitude, subjective norms and perceived behavioural control towards shown Table 5 and Table 6. Moreover, there is no significant

the intention to save in a voluntary saving among the respondent, however further analysis on the permutation test

indicated that the only significant differences between both age group only occurs in the subjective norms. On the other hand, attitude and perceived behavioural control towards the intention to save in a voluntary retirement fund in the two groups (below 30 and above 30 group) shows no significant permutation differences.

Therefore, the test hypothesis $\mathrm{H} 2$ is supported while hypothesis $\mathrm{H} 1$ and $\mathrm{H} 3$ is not, such that the measures and variance in the observe group 1 (Age 30 and below) showed no significant difference with the observation in Group 2 (Above 30) in terms of their attitude, and perceived behavioural control, but a significant difference between subjective norms towards the intention to save in a voluntary retirement fund.

The configural invariance, the measurement model and structural model assessment were done before employing the permutation-based test procedure to compare groups using 5000 permutations for the stability of the result [29]. The Configural and the compositional invariance on the model were done using the MICOM procedure. The result obtained in the MICOM analysis supported partial measurement invariance for the two groups of data. The hypotheses show there is no significant difference between those age 30 and below (Group 1) and above 30 (Group 2) on attitude and perceived behavioural control towards their intention to save in a voluntary retirement fund. However, the permutation $\mathrm{p}$-value indicates there is a significant relationship between subjective norms and the intention to save in a voluntary retirement fund among the younger and older samples. Therefore, it is concludedthat age does not moderate the effect of attitude, and perceived behavioural control towards saving intention of the voluntary private retirement fund, but it moderates the effect of subjective norms towards the intention to save in this fund.

\section{DISCUSSION}

The TPB model posited that attitude, subjective norms and perceived behavioural control will influence behavioural intention but does not distinguish group differences regarding the antecedent of behavioural intention towards intention. At the same time, the life-cycle model assumed that rational manwouldtend to increase their life savings, before consuming their saving on retirement to increase intertemporal utility according to the phase of age. 


\section{Age Differences on the Intention to Save in a Voluntary Retirement Fund}

The life cycle theory suggested there will be differences in term of age and their rationality towards retirement saving. Older workers are more focused on retirement than younger workers, and being more experienced, in a better position, and a higher earner have more money to set aside in savings than low earners [74]. The moderation analysis is essential to close the gaps between these theories to gauge if attitude, subjective norms and perceived behavioural control towards the intention to save are different between age group.

The group-specific investigation shows that for both groups the attitude, subjective norms, and perceived behavioural control will influence a person's saving intention albeit with a varying degree. The result of group-specific path relationship analysis shows that the most important determinant for saving intention for the younger group is the perceived behavioural control, followed by attitude and subjective norms. For the older group the most crucial determinant is not $\mathrm{PBC}$ but their attitude towards saving, followed by PBC and subjective norms. Making a comparison from a bird eye views could lead to a wrong interpretation; therefore, these differences requires further analysis. Employing the permutation p-value results through the Multigroup analysis confirm there are no significant differences between the younger and older group regarding their attitude and PCB towards their behavioural intention to save in a voluntary retirement fund. However, the same test supports the hypothesis regarding the differences between the age groups on subjective norms towards the intention to save in a voluntary retirement fund in Malaysia. It can be inferred that as a person gets older, their intention to save in a voluntary retirement fund are strengthened by their subjective norms, such as the view and the oppinion of their family, peers, employers and the financial advisors.

\section{Conclusion}

The finding of the moderating analysis offers two crucial theoretical consideration. Firstly, it shows the power of TPB to predict the general behaviour regarding attitude, subjective norms, and perceived behavioural control even across different age group. It showed that in both groups the intention to save in a voluntary retirement fund is determined by an individual's attitude, subjective norms and perceived behavioural control. Secondly, it shows that behavioural difference across age exist regarding the subjective norms, which have a role in determining the age differences in the savings intention if the life cycle theory's assumption is to remains constant. The repercussion of this analysis is significant because it indicates that generally the TPB explain the behavioural intention of the Malaysian workers is indicative of age, specifically regarding the subjective norms thus in part, it is not contradicting, nor does it support the assumption of the Life-cycle Theory. The findings show subjective norms will have a stronger effect towards the older group (Group 1: Above 30), as opposed to the younger respondent (Group 2: 30 and Below).

To the researcher knowledge, this study is the first to investigate the age group difference using TPB. The early empirical model focuses exclusively on voluntary retirement saving relied on neoclassical lifecycle framework and incorporated demographic factor such as age and income as a crucial explanatory variable. The socio-demographic factors have long recognised as relevant in influencing behavioural intention; prior research has not considered the TPB to predict the socio-demographic characteristic of an individual in the field of voluntary retirement fund saving intention. This study also has provided a considerable empirical example that even if the individuals are divided into the age group, there is a significant difference on a view about the subjective norms towards saving intention.

This study offers substantial insights into all the party involved, be it the government, and business entity, and the citizens alike. The result of this study has a practical implication to the policy-makers, likewise tocommercial's agencies and marketers. Therefore, when planning for any policies, the findings of this current study should be taken into consideration if the focus is to increasetake up and contribution to the voluntary retirement fund. Simultaneously, the life cycle economist hypothesised that man are rational and will increase saving as their age progresses, while the life-cycle behaviourist suggested that a person will respond to self-control program [20]. One possible recommendation from this study is that any intervention exercise,or promotional program should differregarding their age. As an example, a younger person requires intervention which increases their perceived behavioural control, as such the cash incentive to set up an account in a Voluntary Retirement Fund in Malaysia is exclusively given to those under 30 to motivate saving behaviour among the younger generation. On the other hand, the older samples intention to save is greatly influenced by their subjective norms. Thus, organisation level programs are a better alternative rather than a personal marketing effort to increase this saving behaviour. In this increasingly competitive market, commercial organisations providing the voluntary retirement fund can employ strategy and tactics based on the findings of this study. The findings will help the organisation to understand the behavioural factors of their clients and organisation can make a sound decision which in turn, will help the organisation to streamline their marketing strategy and making a profit for the growth of the company. In another note, the interpretation of data needs to be done with caution because of the limitation of this research. For example, the multigroup analysis using PLS-SEM requires the sample to achieve satisfactory cases, and cases should be almost equivalent in size for each group. The sample gathered through the sample selection could not get enough representation of group age especially from older respondent for a more meaningful moderation analysis according to the life cycle hypotheses to gauge. Because of this limitation, the group analysis simply divided the age into two groups of younger and older to satisfy the multi-group analysis requirement. At the same time, data should also be interpreted with caution because respondents are not homogenous in term of education, income, working sectors and profession. Further research should leverage this information to come out with a more conclusive result. 


\section{ACKNOWLEDGMENT}

Mohamad Fazli Sabri and Radduan Yusof received funding from the Putra Graduate Initiative Grant (IPS), Universiti Putra Malaysia (Project Number 9602800, Vote Number 13201).

\section{REFERENCES}

1. P. Antolin, "Private pensions and the financial crisis: How to ensure adequate retirement income from DC pension plans.," OECD J. Financ. Mark. Trends, vol. 2009, no. 2, pp. 153-174, 2010. Protection in Malaysia," Malaysian J. Econ. Stud. Popul. Ageing Soc. Prot. Malaysia Malaysian J. Econ. Stud., vol. 50, no. 502, pp. 139-156, 2013.

3. R. Holzmann, "Old-Age Financial Protection in Malaysia: Challenges and Options," Bonn, 96, 2015.

4. M. F. Sabri and T. T. Juen, "The Influence of Financial Literacy, Saving Behaviour, and Financial Management on Retirement Confidence among Women Working in the Malaysian Public Sector," Asian Soc. Sci., vol. 10, no. 14, 2014.

5. S. K. Sharma, "Malaysia: Updating and Improving the Social Protection Index," 2012.

6. M. F. Sabri and N. F. Zakaria, "Financial well-being among young employees in Malaysia," in Handbook of research on behavioral finance and investment strategies: Decision making in the financial industry, Z. Copur, Ed. Hershey,USA: IGI Global, 2015, pp. 221-235.

7. L. Falahati and M. F. Sabri, "An exploratory study of personal financial well-being determinants: Examining the moderating effect of gender," Asian Soc. Sci., vol. 11, no. 4, pp. 33-42, 2015.

8. S. Khan, O. Tan, N. Khan, and R. Gale Vergara, "Strengthening Social Safety Net for Older People in Malaysia," J. Southeast Asian Res., vol. 2017, pp. 1-10, Jan. 2017.

9. R. Mohidin, A. A. A. Jamal, C. Geetha, L. T. Sang, and M. R. A. Karim, "Revisiting the Relationship Between Attitudes and Retirement Planning Behavior: A Study on Personal Financial Planning," Int. J. Multidiscip. Thought, vol. 3, no. 2, pp. 449-461, 2013.

10. R. Holzmann, "Global Pension Systems and Their Reform: Worldwide Drivers, Trends and Challenges," Int. Soc. Secur. Rev., vol. 66, no. 2, pp. 1-29, 2013.

11. D. Adascalitei and S. Domonkos, "Reforming against all odds: Multi-pillar pension systems in the Czech Republic and Romania,"

12. M. Naczyk, "Agents of Privatization? Business Groups and the Rise of Pension Funds in Continental Europe," Socio-Economic Rev., vol. 11, no. 3, pp. 441-469, 2013.

13. D. Teusta, "The Challenge of Encouraging Voluntary Savings," in Opportunities and Challenges in the Investment of Pension Funds and Voluntary Pension Savings Funds, 2016, pp. 285-302.

14. A. Ando and F. Modigliani, "The 'Life Cycle' hypothesis of saving: Aggregate implications and tests," Source Am. Econ. Rev., vol. 53, no. 1, pp. 55-84, 1963.

15. F. Modigliani, "Life Cycle, Individual Thrift, and the Wealth of Nations," Science (80-. )., vol. 234, no. 4777, pp. 704-712, Nov. 1986.

16. K. Gythfeldt, A. Kruse, and M. Nordin, "Modigliani's Life Cycle Hypothesis presence amongst Norwegian pensioners Master Thesis," 2008.

17. R. Blundell, C. Emmerson, and M. Wakefield, "The importance of incentives in influencing private retirement saving: known knowns and known unknowns," Institute for Fiscal Studies, London, WP06/09, Apr. 2006.

18. M. F. Mansor, C. Choon Hong, N. Hidayah Abu, and M. Shahidan Shaari, "Demographic Factors Associated with Retirement Planning: A Study of Employees in Malaysian Health Sectors," Asian Soc. Sci., vol. 11, no. 13, p. 108, May 2015.

19. N. Vermeer, M. van Rooij, and D. J. van Vuuren, "Social Interactions and the Retirement Age," SSRN Electron. J., no. 426, 2014.

20. R. G. Hubbard, J. Skinner, and S. P. Zeldes, "Expanding the life-cycle model: Precautionary saving and public policy," The American Economic Review, vol. 84, no. 2. pp. 174-179, 1994.

21. H. M. Shefrin and R. H. Thaler, "The Behavioral Life-cycle Hypothesis," Econ. Inq., vol. 26, no. 4, pp. 609-643, Oct. 1988.

22. T. J. Mahlanza, "Factors Influencing Retirement Savings Intentions in Botswana," Deakin Universit, 2015. retirement savings decisions: Do people care what employers and the government want?," Aust. J. Psychol., vol. 64, no. 2, pp. 83-91, Jun.
2. S. A. Samad and N. Mansor, "Population Ageing and Social Int. Soc. Secur. Rev., vol. 68, no. 2, pp. 85-104, 2015.

23. G. Croy, P. Gerrans, and C. Speelman, "Normative influence on

2012.

24. J. Feng and P. Gerrans, "Understanding superannuation contribution decisions: Theory and evidence," Monash, 2014

25. C. Nosi, A. D’Agostino, M. Pagliuca, and C. A. Pratesi, "Securing retirement at a young age. exploring the intention to buy longevity annuities through an extended version of the Theory of Planned Behavior," Sustain., vol. 9, no. 6, 2017.

26. C. Nosi, A. D'Agostino, M. Pagliuca, and C. A. Pratesi, "Saving for old age: Longevity annuity buying intention of Italian young adults," J. Behav. Exp. Econ., vol. 51, pp. 85-98, Aug. 2014.

27. I. Ajzen and M. Fishbein, "Attitude-behavior relations: A theoretical analysis and review of empirical research.," Psychol. Bull., vol. 84, no. 5, pp. 888-918, Aug. 1977.

28. W. W. Chin and J. Dibbern, "An introduction to a permutation based procedure for multi-group PLS analysis: Results of tests of differences on simulated data and a cross cultural analysis of the sourcing of information system services between Germany and the USA," in Handbook of Partial Least Squares, V. E. Vinzi, W. Chin, J. Henseler, and H. Wang, Eds. Berlin, Heidelberg: Springer Berlin Heidelberg, 2010, pp. 171-193.

29. L. Matthews, "Applying multigroup analysis in PLS-SEM: A step-by-step process," in Partial Least Squares Path Modeling: Basic Concepts, Methodological Issues and Applications, H. Latan and R. Noonan, Eds. Cham, Switzerland: Springer, 2017, pp. 219-243.

30. F. Modigliani and R. H. Brumberg, "Utility Analysis and the Consumption Function: an interpretation of cross-section data," in Post-Keynesian Economics, K. K. Kurihara, Ed. New Brunswick, NJ: Rutgers University Press, 1954, pp. 388-436.

31. S. Nayak and N. Sethi, "Determinants and Pattern of Saving Behaviour in Rural Households of Western Odisha," National Institute of Technology, Rourkela, India, 2013.

32. A. Lusardi, P. Michaud, and O. S. Mitchell, "Optimal Financial Literacy and Saving for Retirement," WR-905-SSA, 2011.

33. N. F. M. Talib and H. A. Manaf, "Attitude towards Retirement Planning Behaviour among Employee's," J. Bus. Manag., vol. 1, no. 1, pp. 15-21, 2017.

34. M. K. Moorthy et al., "A Study on the Retirement Planning Behaviour of Working Individuals in Malaysia," Int. J. Acad. Res. Econ. Manag. Sci., vol. 1, no. 2, pp. 2226-3624, 2012.

35. A. H. Munnell, A. Sunden, and C. Taylor, "What Determines 401 (k) Participation and Contributions," Chestnut Hill, MA 02467, CRR WP 2000-12, 2000.

36. D. A. Hershey and J. C. Mowen, "Psychological Determinants of Financial Preparedness for Retirement," Gerontologist, vol. 40, no. 6, pp. 687-697, Dec. 2000.

37. N. Keating and J. Marshall, "The process of retirement: The rusal self-employed," Gerontologist, vol. 20, pp. 437-443, 1980.

38. T. K. Hira, W. L. Rock, and C. Loibl, "Determinants of Retirement Planning Behaviour and Differences by Age," Int. J. Consum. Stud., vol. 33, no. 3, pp. 293-301, May 2009.

39. I. Ajzen, "Nature and operation of attitudes," Annu. Rev. Psychol., vol. 52, no. 1, pp. 27-58, Feb. 2001

40. I. Ajzen, "From intentions to actions: A Theory of Planned Behavior," in Action control: From cognition to behavior, J. Kuhl and J. Beckman, Eds. Berlin, Heidelberg: Springer Berlin Heidelberg, 1985, pp. 11-39.

41. K. Mathieson, "Predicting User Intentions: Comparing the Technology Acceptance Model with the Theory of Planned Behavior," Inf. Syst. Res., vol. 2, no. 3, pp. 173-191, Sep. 1991.

42. T. Teo, M. Zhou, and J. Noyes, "Teachers and technology: development of an extended theory of planned behavior," Educ. Technol. Res. Dev., vol. 64, no. 6, pp. 1033-1052, Dec. 2016.

43. J. Kim, J. Kwon, and E. A. Anderson, "Factors Related to Retirement Confidence: Retirement Preparation and Workplace Financial Education," Financ. Couns. Plan., vol. 16, no. 2, pp. 77-89, 2005.

44. E. Duflo and E. Saez, "Participation and Investment Decisions in a Retirement Plan: The Influence of Colleagues' Choices," J. Public Econ., vol. 85, pp. 121-148, 2002.

45. I. Ajzen and M. Fishbein, "Theory of reasoned action/Theory of planned behavior," Univ. South Florida, vol. 2007, pp. 67-98, 1988.

46. K. Henkens, "Retirement intentions and spousal support: a multi-actor approach.," J. Gerontol. B. Psychol. Sci. Soc. Sci., vol. 54, no. 2, pp. S63-73, Mar. 1999.

47. I. Ajzen, "The theory of planned behavior," Organ. Behav. Hum Decis. Process., vol. 50, no. 2, pp. 179-211, Dec. 1991. 


\section{Age Differences on the Intention to Save in a Voluntary Retirement Fund}

48. D. P. Johnson, "How Attitude Toward the Behavior, Subjective Norm, and Perceived Behavioral Control Affects Information Security Behavior Intention," Walden University, 2017.

49. I. Botetzagias, A.-F. Dima, and C. Malesios, "Extending the Theory of Planned Behavior in the context of recycling: The role of moral norms and of demographic predictors," Resour. Conserv. Recycl., vol. 95, pp. 58-67, Feb. 2015.

50. M. T. Al-Ziadat, "Applications of planned behavior theory (TPB) in Jordanian tourism," Int. J. Mark. Stud., vol. 7, no. 3, pp. 95-106, 2015.

51. J. F. Hair, C. M. Ringle, and M. Sarstedt, "PLS-SEM: Indeed a Silver Bullet," J. Mark. Theory Pract., vol. 19, no. 2, pp. 139-152, Apr. 2011.

52. J. M. Becker, A. Rai, C. M. Ringle, and F. Volckner, "Discovering unobserved heterogeneity in structural equation models to avert validity threats," MIS Q., vol. 37, no. 3, pp. 665-694, 1977.

53. J. F. Hair, M. Sarstedt, C. M. Ringle, and S. P. Gudergan, Advanced Issues in Partial Least Squares Structural Equation Modeling. California: Sage Publication Inc, 2018.

54. J. Henseler, C. M. Ringle, and M. Sarstedt, "Testing measurement invariance of composites using partial least squares," Int. Mark. Rev., vol. 33, no. 3, pp. 405-431, May 2016.

55. W. W. Chin, "How to Write Up and Report PLS Analyses," in Handbook of Partial Least Squares, Berlin, Heidelberg: Springer Berlin Heidelberg, 2010, pp. 655-690.

56. G. Croy, P. Gerrans, and C. P. Speelman, "A mediating role for anticipated regret in predicting retirement savings intention between groups with (without) past behaviour," Aust. J. Psychol., vol. 67, no. 2, pp. 87-96, Jun. 2015.

57. G. Croy, P. Gerrans, and C. Speelman, Psychological determinants of retirement savings behaviour: An application of the theory of planned behaviour. Lambert Academic Publishing, Edith Cowan University, 2012.

58. J. C. Nunnally, Psychometric theory. McGraw-Hill, 1978.

59. J. F. Hair, M. Sarstedt, L. Hopkins, and V. Kuppelwieser, "Partial least squares structural equation modeling (PLS-SEM)," Eur. Bus. Rev., vol. 26, no. 2, pp. 106-121, 2014

60. W. W. Chin, A. M. Mills, D. J. Steel, and A. Schwarz, "Multi-Group invariance testing: An illustrative comparison of PLS permutation and covariance-based SEM invariance analysis," in 7th International Conference on Partial Least Squares and Related Methods, 2012, pp. $1-11$.

61. J. F. Hair, G. T. M. Hult, C. M. Ringle, and M. Sarstedt, A Primer on Partial Least Squares Structural Equation Modeling (PLS-SEM), 2nd ed. Thousand Oaks: Sage, 2017.

62. V. E. Vinzi, L. Trinchera, and S. Amato, "PLS Path Modeling: From Foundations to Recent Developments and Open Issues for Model Assessment and Improvement," in Handbook of Partial Least Squares, no. July, V. Esposito Vinzi, W. W. Chin, J. Henseler, and H. Wang, Eds. Berlin, Heidelberg: Springer Berlin Heidelberg, 2010, pp. 171-193.

63. J.-B. E. . Steenkamp and F. Ter Hofstede, "International market segmentation: issues and perspectives," Int. J. Res. Mark., vol. 19, no. 3, pp. 185-213, Sep. 2002.

64. J. Henseler and G. Fassott, "Testing Moderating Effects in PLS Path Models: An Illustration of Available Procedures," in Handbook of Partial Least Squares, Berlin, Heidelberg: Springer Berlin Heidelberg, 2010, pp. 713-735.

65. J. Henseler, "PLS-MGA: A Non-Parametric Approach to Partial Leas Squares-based Multi-Group Analysis," in Challenges at the Interface of Data Analysis, Computer Science, and Optimization - Proceedings of the 34th Annual Conference of the Gesellschaft für Klassifikation e. V., Karlsruhe, July 21 - 23, 2012, pp. 495-501.

66. M. Sarstedt, J. Henseler, and C. M. Ringle, "Multigroup Analysis in Partial Least Squares (PLS) Path Modeling: Alternative Methods and Empirical Results," in The use of partial least squares path modeling in international marketing, vol. 22, P. S. Zou, Ed. Emerald Group Publishing Limited, 2011, pp. 195-218.

67. G. T. M. Hult et al., "Data equivalence in cross-cultural international business research: assessment and guidelines," J. Int. Bus. Stud., vol. 39, no. 6, pp. 1027-1044, Sep. 2008.

68. J. Henseler, C. M. Ringle, and M. Sarstedt, "A new criterion for assessing discriminant validity in variance-based structural equation modeling," J. Acad. Mark. Sci., vol. 43, no. 1, pp. 115-135, 2014.

69. J.-B. E. . Steenkamp and H. Baumgartner, "Assessing Measurement Invariance in Cross-National Consumer Research," J. Consum. Res., vol. 25, no. 1, pp. 78-90, 1998.

70. R. J. Vandenberg and C. E. Lance, "A Review and Synthesis of the Measurement Invariance Literature: Suggestions, Practices, and Recommendations for Organizational Research," Organ. Res. Methods, vol. 3, no. 1, pp. 4-70, Jan. 2000.
71. A. Diamantopoulos and N. Papadopoulos, "Assessing the cross-national invariance of formative measure: guidelines for international business researchers," J. Int. Bus. Stud., vol. 41, no. 2 , pp. 360-70, 2010

72. D. Gefen, D. W. Straub, and M.-C. Boudreau, "Structural Equation Modeling and and Regresion: Guideline for Research Practice,' Commun. AIS, vol. 4, no. 7, 2000.

73. T. Ramayah, J. Cheah, F. Chuah, H. Ting, and M. A. Memon, Partial Least Squares Structural Equation Modeling (PLS-SEM) using SmartPLS 3.0: An Updated and Practical Guide to Statistical Analysis, 2nd ed. Kuala Lumpur: Pearson Malaysia Sdn. Bhd., 2018.

74. P. Yakoboski and J. VanDerhei, "Worker Investment Decisions: An Analysis of Large 401(k) Plan Data,” 1996.

\section{AUTHORS PROFILE}

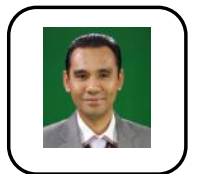

Assoc. Prof. Dr. Mohamad Fazli Sabri is currently the Deputy Dean (Post Graduate Studies \& Industry \& Community Relations) of the Faculty of Human Ecology at Universiti Putra Malaysia.He began his academic careerafter completing a Bachelor of Science in Human Development, majoring in Resource Management and Consumer Studies at Universiti Putra Malaysia. He then moved forward when he received a Master of Consumer Science at Universiti Putra Malaysia and finally obtained a PhD from Iowa State University, USA, specializing in Family Finance. Fazli also holds professional qualifications such as the Registered Financial Planner (RFP) designation from the Malaysian Financial Planning Council (MFPC) and the globally recognised Certified Financial Planner (CFP) designation from the Financial Planning Association of Malaysia (FPAM). He also holds a Diploma and Advanced Diploma in Technical and Vocational Training (TVET) specializing in Financial Planning from the Department of Skills Development, Ministry of Human Resources Malaysia.

Fazli actively participates as a speaker as well as paper presenter in various national and internationalseminars, conferences and intellectualdiscourses He has presented papers in the United States, Australia, Turkey, China and Indonesia. His ability beyond Malaysian borders was demonstrated when he was invited as a visiting professor at the Faculty of Human Ecology, Bogor Agricultural University and subsequently appointed as the Country President for the Scholars Academic and Scientific Society and a member of the editorial board of the journal. Currently he also hold various position at the international such as Vice President for Asian Association for Consumer Interest and Marketing (AACIM), Board of Director for International Academy for Financial Consumers (IAFICO) and Executive Board Member for Scholars Academic and Scientific Society. His expertise in personal finance management is evident as he was requested to be a columnist on the financial page in Kosmo!., a leading newspaper in Malaysia. This column appears every fortnight. In addition, he is often invited as a panellist to discuss consumer finance matters on radio and television. Fazli also is a National Council Member of the Malaysian Financial Planning Council and an exco member of the Malaysian Consumer and Family Economics Association (MACFEA)

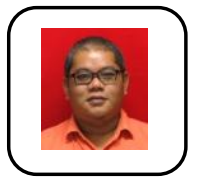

Dr Radduan Yusofis a senior lecturer at the Faculty of Administrative Science and Policy Studies in UniversitiTeknologi Mara (UiTM) Seremban 3 and has been serving the University for 12 years. He received his doctorate 2019 in the field of Family Economic and Management at the Faculty of Human Ecology, University Putra Malaysia. Prior to that, he graduated with a Bachelor of Economics (Public Administration) Honors from the University of Malaya in 1998, and a master's degree in Public Administration in 2003 from the same university. 